\title{
Multimodality imaging in transcatheter aortic valve implantation (TAVI): comparison between cardiovascular magnetic resonance, cardiac computed tomography and echocardiography
}

\author{
Jabbour Andrew ${ }^{1 *}$, Francois Okoroafor ${ }^{1}$, Bradley Park², Isabelle Roussin², Francisco Alpendurada ${ }^{1}$, Tevfik Ismail ${ }^{1}$, \\ Maria N Paes ${ }^{3}$, Simon Davies ${ }^{1}$, Michael J Mullen ${ }^{1}$, Nicola Delahunty' ${ }^{1}$ Sanjay Prasad ${ }^{1}$, Michael Rubens', \\ Neil Moat ${ }^{1}$, Raad Mohiaddin ${ }^{1}$
}

From 2011 SCMR/Euro CMR Joint Scientific Sessions Nice, France. 3-6 February 2011

\section{Background}

Patients considered for TAVI often undergo several cardiac imaging investigations during assessment. Although each imaging modality has its particular advantages, not all imaging modalities are universally available. This study sought to determine the agreement and variability of cardiovascular magnetic resonance (CMR), electrocardiograph-gated cardiac computed tomography (cardiac $\mathrm{CT}$ ) and transthoracic echocardiography in the assessment of aortic root size and morphology.

\section{Methods}

Patients undergoing TAVI assessment with CMR, cardiac CT and echocardiography, were recruited to the study. Agreement and variability between each imaging modality in the measurement of aortic annulus, sinus of valsalva, sinotubular junction and ascending aorta dimensions was assessed by Bland-Altman analysis. Intraobserver and interobserver variability was also assessed and compared.

\section{Results}

Of 201 patients undergoing TAVI assessment with both CMR and Echocardiography, 133 also underwent an ECG-gated Cardiac CT scan. Close agreement was observed between CMR and Cardiac CT in the assessment of aortic annulus dimensions (Bias $-0.4 \mathrm{~mm}$, SD of Bias $2.7 \mathrm{~mm}, 95 \%$ Limits of agreement $-5.7 \mathrm{~mm}$ to

'Royal Brompton Hospital and Imperial College, London, UK

Full list of author information is available at the end of the article

$5.0 \mathrm{~mm}$ ), sinus of valsalva dimensions (Bias $-0.6 \mathrm{~mm}, \mathrm{SD}$ of Bias $2.5 \mathrm{~mm}, 95 \%$ Limits of agreement $-4.3 \mathrm{~mm}$ to $5.5 \mathrm{~mm}$ ), sinotubular junction dimensions (Bias $-0.7 \mathrm{~mm}$, SD of Bias $2.4 \mathrm{~mm}$, $95 \%$ Limits of agreement $-5.3 \mathrm{~mm}$ to $3.9 \mathrm{~mm}$ ), and ascending aorta dimensions at the level of the right pulmonary artery (Bias $-0.1 \mathrm{~mm}$, SD of Bias $2.6 \mathrm{~mm}, 95 \%$ Limits of agreement $-5.3 \mathrm{~mm}$ to $5.1 \mathrm{~mm}$ ).

Agreement between echocardiography-derived measures and either CMR or Cardiac CT was less tight. CMR to echocardiography agreement in aortic annulus dimensions (Bias $-4.0 \mathrm{~mm}$, SD of Bias $6.5 \mathrm{~mm}$, 95\% Limits of agreement $-16.7 \mathrm{~mm}$ to $8.8 \mathrm{~mm}$ ), sinus of valsalva dimensions (Bias $-0.7 \mathrm{~mm}$, SD of Bias $4.5 \mathrm{~mm}$, 95\% Limits of agreement $-9.6 \mathrm{~mm}$ to $8.1 \mathrm{~mm}$ ), sinotubular junction dimensions (Bias $-2.1 \mathrm{~mm}$, SD of Bias $4.7 \mathrm{~mm}$, 95\% Limits of agreement $-11.2 \mathrm{~mm}$ to $7.1 \mathrm{~mm}$ ), and ascending aorta dimensions at the level of the right pulmonary artery (Bias $-0.0 \mathrm{~mm}$, SD of Bias $4.0 \mathrm{~mm}$, 95\% Limits of agreement $-7.8 \mathrm{~mm}$ to $7.8 \mathrm{~mm}$ ). Intraobserver and interobserver variability was lowest in CMR-derived measures followed by Cardiac CT then transthoracic echocardiography.

\section{Conclusions}

In patients undergoing assessment for TAVI, close agreement exists between CMR and ECG-gated Cardiac $\mathrm{CT}$ in the assessment of aortic root dimensions. Low intraobserver and interobserver variability was seen in both modalities, although best with CMR. Lower 
agreement and higher variability was observed between echocardiography and the other two imaging modalities.

\title{
Author details
}

${ }^{1}$ Royal Brompton Hospital and Imperial College, London, UK. ${ }^{2}$ Royal

Brompton Hospital, London, UK. ${ }^{3}$ Imperial College, London, UK.

Published: 2 February 2011

\begin{abstract}
doi:10.1186/1532-429X-13-S1-051
Cite this article as: Andrew et al:: Multimodality imaging in

transcatheter aortic valve implantation (TAVI): comparison between

cardiovascular magnetic resonance, cardiac computed tomography and echocardiography. Journal of Cardiovascular Magnetic Resonance 201113 (Suppl 1):051.
\end{abstract}

Submit your next manuscript to BioMed Central and take full advantage of:

- Convenient online submission

- Thorough peer review

- No space constraints or color figure charges

- Immediate publication on acceptance

- Inclusion in PubMed, CAS, Scopus and Google Scholar

- Research which is freely available for redistribution

Submit your manuscript at www.biomedcentral.com/submit
Ciomed Central 